\title{
Outcome of ultrasound-guided, single session pleurodesis in malignant pleural effusion
}

\author{
Khalil M. Magdy and Ezzelregal G. Hieba*
}

\begin{abstract}
Background: Chemical pleurodesis is frequently indicated to relieve symptoms imposed by large/recurrent malignant pleural effusion (MPE). Traditionally, a drain is left in the pleural space till the cessation of fluid accumulation before pleurodesis. Chest ultrasound can detect an amount of pleural fluid as less as $50 \mathrm{ml}$ and can confirm apposition of the pleural surfaces which is required for successful pleurodesis. This work assessed the efficiency and safety of ultrasoundguided, single-session pleurodesis in cases with MPE.

Results: Seventeen of the patients completed a 2-month follow-up. The technique demonstrated a high success rate (88.2\%). The mean duration from the start of pleural drainage till pleurodesis was $1.65 \pm 0.70 \mathrm{~h}$ ranging from 1 to $3 \mathrm{~h}$. A duration of $2.5 \mathrm{~h}$ or less was statistically proposed as a cutoff value not to exceed to predict success (sensitivity 100\%, specificity 100\%). The mean time for total hospital stay related to pleurodesis was $9.88 \pm 3.12 \mathrm{~h}$ (range $4-12 \mathrm{~h}$ ). No complications attributed to the procedure were recorded. Pleural Adherence Score and Absent Sliding Score (ASS) had a highly statistically significant correlation ( $p$ value $<0.001$ ).

Conclusions: An ultrasound-guided completion of the process of pleurodesis in a single session with a shorter duration of pleural fluid drainage and shorter hospital stay (can be done on a day-care basis) is efficient, safe, and costeffective. This technique is strongly recommended to replace the traditional practice of keeping the indwelling pleural drain for several days waiting for the cessation of pleural fluid reaccumulation. An ultrasound-derived ASS can be used as early as day 1 and day 15 to confirm pleural adherence and to expect the outcome of pleurodesis.
\end{abstract}

Keywords: Malignant pleural effusion, Pleurodesis, Chest ultrasound

\section{Background}

Malignant pleural effusion is a common complication of advanced stages of malignancies [1]. Large and/or recurrent effusion adds to morbidity, and prevention of reaccumulation through pleurodesis improves the quality of life of those patients.

The most important requirement for successful pleurodesis is the satisfactory apposition of the parietal and visceral pleurae [2]. Traditionally, the pleural drain is left in situ till a minimal pleural fluid of $50-100 \mathrm{ml}$ is collected over $24 \mathrm{~h}$ before pleurodesis is started. This process usually takes several days, and this is confirmed with serial chest X-rays.

Chest ultrasound is sensitive in detecting an amount of pleural fluid as less as $50 \mathrm{ml}$ and can confirm apposition of the pleural surfaces [3]. In this work, we used chest ultrasound to verify that pre-requisites of successful pleurodesis are fulfilled and to accomplish the task in a single session after complete drainage of pleural fluid in cases with malignant pleural effusion.

The aim of this work was to assess the efficiency and safety of ultrasound-guided, single-session pleurodesis in cases with malignant pleural effusion.

\footnotetext{
* Correspondence: drhebaezz111213@gmail.com

Chest Department, Ain Shams University, Cairo, Egypt
}

\section{Springer Open}

(c) The Author(s). 2020 Open Access This article is licensed under a Creative Commons Attribution 4.0 International License, which permits use, sharing, adaptation, distribution and reproduction in any medium or format, as long as you give appropriate credit to the original author(s) and the source, provide a link to the Creative Commons licence, and indicate if changes were made. The images or other third party material in this article are included in the article's Creative Commons licence, unless indicated otherwise in a credit line to the material. If material is not included in the article's Creative Commons licence and your intended use is not permitted by statutory regulation or exceeds the permitted use, you will need to obtain permission directly from the copyright holder. To view a copy of this licence, visit http://creativecommons.org/licenses/by/4.0/. 


\section{Methods}

This study was a prospective observational study, conducted in the Chest Department, Ain Shams University Hospitals, during the period from June 2017 till March 2019 on 20 patients (15 females and 5 males) admitted with malignant pleural effusion (MPE) and recommended for pleurodesis.

The diagnosis of malignant pleural effusion is based on the presence of malignant and/or atypical cells in the pleural fluid within a clinical context impressive of malignant neoplastic disease.

The following are the exclusion criteria:

- Patients who refused to participate in the trial

- Patients with multiloculated effusion or previously failed pleurodesis

- Patients with comorbidity that may affect the process of pleurodesis, e.g., receiving NSAIDs, hepatic insufficiency

The study was approved by the Ethical Committee Board of Ain Shams University and in accordance with the Declaration of Helsinki.

After an informed verbal consent from all enrolled patients, all were subjected to the following:

1. Clinical assessment

2. Radiological assessment: CXR and/or chest CT whichever available

3. Complete blood count ( $\mathrm{CBC})$, liver and kidney function tests, total protein, serum albumin, and $\mathrm{C}$ reactive protein (CRP)

4. Revision of cytopathological results of pleural fluid/ biopsy

5. Ultrasonographic assessment: The assessment was done using Mindray DP-1100 Shanghai, China, in Ain Shams diagnostic ultrasound unit. All cases were examined by $\mathrm{B}$ mode and $\mathrm{M}$ mode with curvilinear transducer $(3.5 \mathrm{MHz})$ to assess the presence of the sliding sign, the amount of pleural fluid, and the presence of any loculations before the insertion of a pigtail. While the patient was sitting with arms extended and resting on a firm surface that is just below the level of the shoulders, all anatomical areas of the affected side of the lung were examined: anterior-infraclavicular, mammary, inframammary, and upper axillary and lower axillary; back-suprascapular, interscapular, and infrascapular.

6. Pigtail insertion and fluid drainage were done under sonographic guidance. As much fluid as possible (maximum $1.5 \mathrm{l} / \mathrm{h}$ ) was drained each time unless there is a contraindication to continue as regards patient hemodynamics or development of complications such as persistent cough, chest discomfort, or vasovagal attack. Repeated drainage every $1 \mathrm{~h}$ was done till complete drainage followed by aspiration of any remaining fluid as documented by US.

7. Pleurodesis: Injection of $30 \mathrm{ml}$ of $2 \%$ lidocaine into the pleural space through the pigtail followed by injection of doxycycline. An oral form of doxycycline was used, at a dose of 10 $\mathrm{mg} / \mathrm{kg}$ body weight. The particles of doxycycline capsules were evacuated under complete aseptic technique in a container, then dissolved in $30 \mathrm{ml}$ normal saline and instilled through the pigtail, followed by $20 \mathrm{ml}$ of normal saline to clean the pigtail and to push all dissolved doxycycline to the pleural space.

8. The pigtail was then clamped for $2 \mathrm{~h}$.

9. The pleural cavity was reassessed by US with aspiration of remaining fluid, and the pigtail was removed.

10. Pleural Adherence Score (PAS) on day 1 was recorded: Pleural Adherence Score was scored in nine zones (upper, middle, and lower zones in the anterior, lateral, and posterior chest wall) across the affected hemithorax in real-time ultrasonography as present $(=0)$, questionable $(=1)$, or absent $(=2)$, generating a total Pleural Adherence Score of 18 for the hemithorax [4].

11. Reassessment by ultrasound 15 days after pleurodesis: Recording of absence/presence of sliding sign in the 9 standard points as $(\mathrm{A}, \mathrm{B}, \mathrm{C})$ : $A$-absent sliding in more than 6 areas; $B$-absent in 6 areas to more than 3 areas; $C$-absent in 3 areas or less generating a newer simpler Absent Sliding Score (ASS) of 9 points for the hemithorax.

12. Re-evaluation by ultrasonography was done 2 months later for the recurrence of pleural effusion.

13. Documentation of the outcome as regards the amount of fluid drained, pleurodesis failure (fluid recurrence in the ipsilateral hemithorax requiring another therapeutic pleural intervention with radiological evidence by chest US or fluid recurrence at any point during follow-up) [4], development of complications, and total hospital stay related to the procedure.

Data analysis was done using the computer program SPSS (Statistical Package for the Social Science; SPSS Inc., Chicago, IL, USA) release 15 for Microsoft Windows (2006). Qualitative variables were presented as the percentage, and quantitative variables were presented as mean \pm SD. Student's $t$ test and Pearson's correlation coefficient were used as the test of significance; $p$ value less than 0.05 was considered as significant. 


\section{Results}

This was a prospective study that included 20 patients with the diagnosis of malignant pleural effusion, 15 (75\%) females and $5(25 \%)$ males, $57 \pm 17$ years old (range, 25-88 years old). One patient expired early in the first $24 \mathrm{~h}$ of admission with massive pulmonary embolism, another one died lately, and one was missed from a 2-month follow-up. Seventeen patients completed till 2 months of follow-up and were included in the analysis of the results. The clinical and cytopathological features of them are shown in Table 1 .

In this study, pleural fluid of $2815 \pm 881.55 \mathrm{ml}$ was drained over a period of $1.65 \pm 0.70 \mathrm{~h}$ ranging from 1 to $3 \mathrm{~h}$ before pleurodesis. Th volume of pleural fluid $2 \mathrm{~h}$ after pleurodesis as assessed by ultrasound was $33.25 \pm$ $23.64 \mathrm{ml}$. Pleural Adherence Score (PAS) $24 \mathrm{~h}$ after pleurodesis was $13.37 \pm 2.87$. Two weeks after, pleurodesis Absent Sliding Score (ASS) classified as A and B was $52.6 \%$ and $42.1 \%$, respectively (Table 2 ).

In this study, the primary outcome was the success of pleurodesis as judged by no reaccumulation (76.5\%) or minimal encystation (11.7\%) of pleural fluid after 2 months, and secondary outcomes were the occurrence of no complications related to the process of rapid pleural fluid drainage and the duration of hospital stay related to the procedure (Table 3). The mean time for total hospital stay related to pleurodesis was $9.88 \pm 3.12$ $\mathrm{h}$ (ranging from 4 to $12 \mathrm{~h}$ ). This time included the time needed for preparation, performance of the procedure, and time for observation for complications/discomfort after the procedure.

In this study, the shorter the duration of pleural fluid drainage, the highly significant the increase in pleurodesis success, in cases with pleural fluid drained over a shorter duration compared to those with longer duration $(1.47 \pm 0.52$ versus $3.00 \pm 0.00$, respectively, $p$ value 0.001) (Table 4).

Table 1 Clinical and cytopathological features of the studied cases

\begin{tabular}{lll}
\hline & & No. (\%) \\
\hline Side of pleural effusion & Right & $9(52.9 \%)$ \\
& Left & $8(47 \%)$ \\
Pleural fluid cytology & Metastatic adenocarcinoma & $11(64.7 \%)$ \\
& Exudative with atypical cells & $4(23.5 \%)$ \\
& Mesothelioma & $2(10 \%)$ \\
Primary neoplasm & Breast & $8(47 \%)$ \\
& Lung & $4(23.5 \%)$ \\
& Blood & $2(10 \%)$ \\
& Pleura & $2(10 \%)$ \\
& Larynx & $1(5 \%)$ \\
\hline
\end{tabular}

Pleural Adherence Score was higher in those with successful pleurodesis compared to 2 cases with failed pleurodesis, but this did not reach a statistically significant difference ( $p$ value 0.08 ) (Table 4).

In this work, to assess the validity of the duration of pleural fluid drainage for prediction of pleurodesis success, the area under the receiver operating characteristic (ROC) curve for the duration spent in pleural fluid drainage in hours was 1.0. A duration of $2.5 \mathrm{~h}$ or less was statistically proposed as a cutoff value not to exceed for successful pleurodesis (sensitivity 100\%, specificity 100\%) (Fig. 1).

In this study, there was a highly significant correlation between the Pleural Adherence Score (PAS) after 24h and Absent Sliding Score (ASS) after 2 weeks ( $p$ value $<$ 0.001) (Table 5).

In this work, to assess the validity of the Pleural Adherence Score after $24 \mathrm{~h}$ from pleurodesis for prediction of pleurodesis success, the area under the receiver operating characteristic (ROC) curve for total Pleural Adherence Scores after $24 \mathrm{~h}$ was 0.883 . A total Pleural Adherence Score of 11 or more after $24 \mathrm{~h}$ from pleurodesis (sensitivity 93\%, specificity50\%) (Fig. 2) was statistically proposed as a cutoff value for pigtail removal and expected successful pleurodesis.

In this study, there was a statistically significant correlation between duration needed for pleural fluid drainage in hours and the total hospital stay in hours ( $p$ value 0.0039). Though this seems a logic correlation, it also indicates the value of the shortened duration of pleural fluid drainage.

\section{Discussion}

Malignant pleural effusion (MPE) is a very common problem [5], and with old age and more patients with metastatic tumors surviving a long time, the number of cases will continue to rise in the future [6]. Most patients requiring therapeutic drainage for symptomatic relief and patients with recurrent MPE are managed with chemical pleurodesis with different sclerosant [7].

The usual procedure of pleurodesis entails hospitalization, insertion of a pleural drain, and waiting for cessation of pleural fluid accumulation till $50-100 \mathrm{ml} / 24 \mathrm{~h}$, a process which may extend for days. Studies in animals and humans showed that thoracic ultrasound can detect pleural adhesions and absent normal sliding after pleurodesis with different sclerosant [4, 8-10]. In this work, we demonstrated that the completion of the process of pleurodesis (complete aspiration of pleural fluid to ensure apposition of visceral and parietal pleurae followed by instillation of sclerosant) in one session guided by chest ultrasonography is effective, safe, and cost-effective.

This was a prospective observational study, conducted in the Chest Department, Ain Shams University 
Table 2 Ultrasonographic findings of the pleural fluid and the pleura before and after pleurodesis

\begin{tabular}{|c|c|c|}
\hline & Range & Mean \pm SD \\
\hline Amount of fluid drained (ml) & $2000-5500$ & $2815 \pm 881.55$ \\
\hline Duration of drainage $(h)$ & $1-3$ & $1.65 \pm 0.70$ \\
\hline Estimated volume of pleural fluid (with US) $2 \mathrm{~h}$ after pleurodesis (ml) & $0-100$ & $33.25 \pm 23.64$ \\
\hline \multirow[t]{2}{*}{ *PAS $24 \mathrm{~h}$ after pleurodesis } & $5-17$ & $13.37 \pm 2.87$ \\
\hline & $N(\%)$ & \\
\hline \multirow[t]{2}{*}{ **ASS 2 weeks after pleurodesis } & $10(58.8 \%)$ & \\
\hline & $7(41.2 \%)$ & \\
\hline
\end{tabular}

*PAS Pleural Adherence Score: Pleural Adherence Score was scored in nine zones (upper, middle, and lower zones in the anterior, lateral, and posterior chest wall) across the affected hemithorax in real-time as present $(=0)$, questionable $(=1)$, or absent $(=2)$

**ASS Absent Sliding Score: 2 weeks after pleurodesis-A (absent in more than 6 areas) and B (absent in 4 to 6 areas)

Hospitals, on 20 patients who were admitted with malignant pleural effusion (MPE) legible for pleurodesis; 15 (75\%) females and $5(25 \%)$ males, $57 \pm 17$ years old (range, 25-88 years old). Only 17 patients completed till 2 months of follow-up and were included in the analysis.

In this study, metastatic adenocarcinoma (65\%) was the most common cause of MPE, mostly of breast origin (50\%) in concordance with previous recent and old studies $[7,11,12]$.

The rate of success of pleurodesis 2 months after the procedure was $88.2 \%$; complete success with no reaccumulation of pleural fluid in $76.5 \%$ of the cases, and a minimally encysted collection in $11.7 \%$ [part of the right lower axillary area in one patient and part of the right infrascapular area in the other] which was considered as a satisfactory success (Table 3 ).

In this study, the success of pleurodesis was evaluated by three methods. The first was done on day 1 by calculating the previously described PAS. The second was 2 weeks after the procedure by ultrasonographic assessment of pleural sliding (ASS) aiming to simplify the previously mentioned PAS: A (absent sliding in more than 6 areas) was present in 52.6\%, B (absent sliding in 4 to 6 areas) was present in $42.1 \%$, and $C$ (absent sliding in 3 or less areas) was present in $5.3 \%$ of cases. The last one was the traditional one with radiographic assessment for the ipsilateral reaccumulation of pleural fluid. This was done using chest ultrasonography 2 months after the procedure.

In this work, a highly significant correlation was found between these grades of absent sliding (A, B) after 2 weeks and PAS ( $p$ value $<0.001)$ (Table 5$)$. With the increase in PAS, there was an increase in the absent sliding grade. This is really expected as both are indicating pleural adhesions. So, this grade can be used to replace PAS as a more simplified score. Ultrasonographic evaluation of absent sliding sign as an indicator of the success of pleurodesis has two advantages: firstly, earlier evaluation of the outcome and, secondly, direct confirmation of the effect of the instilled sclerosant, namely pleural adhesion. The validity of this method was reported in previous studies $[4,8,13,14]$.

A non-significant correlation, however, was found in the current study between the outcome of pleurodesis and this Absent Sliding Score ( $p$ value 0.15). This is related to the small number of failed pleurodesis in the studied population.

The rate of success was higher than that reported in other studies which used tetracyclin as a sclerosant. In Tettey et al., the success rate was $61 \%$, there was recurrence with loculation in $16 \%$ of the cases, and $23 \%$ of patients had unsuccessful and significant reaccumulation of pleural fluid [12]. Our study results were also noncomparable that of Mourad et al. who used tetracycline pleurodesis with a success rate of $60 \%$ [15]. Others showed success rates of 76\% [1] and 80\% [16]. The latter was carried on a smaller number of patients, 10 patients, and provided no information about the duration of keeping the pleural drain in situ. The higher success rate in the current study is attributed to the technique of pleurodesis used which ascertained almost complete evacuation of the pleural space with good apposition of the pleural surfaces before the instillation of the sclerosant agent and the short duration of the procedure

Table 3 Outcome of single session pleurodesis

No reaccumulation of pleural fluid after 2 months, $N(\%)$ 
Table 4 Factors affecting the outcome

\begin{tabular}{|c|c|c|c|c|c|c|}
\hline & Out & 2 mont & & & $t^{*}$ & $p$ value \\
\hline & Succ & $\pm S D$ & Fail & SD & & \\
\hline Pleural Adherence Score after $24 \mathrm{~h}$ & 14.2 & & 11.5 & & 1.88 & 0.08 NS \\
\hline Residual pleural fluid $2 \mathrm{~h}$ after pleurodesis (ml) & 33.3 & & 32.5 & & 0.07 & 0.95 NS \\
\hline Duration of drainage (h) & 1.47 & & 3.00 & & -4.083 & $0.001 \mathrm{HS}$ \\
\hline Total hospital stay related to the procedure (h) & 9.60 & & 12. & & -1.023 & $0.322 \mathrm{NS}$ \\
\hline & $N$ & $\%$ & N & $\%$ & $\mathrm{FE}^{* *}$ & $p$ value \\
\hline${ }^{* * *}$ ASS & 10 & 100.0 & 0 & 0.0 & 3.24 & 0.15 NS \\
\hline B & 5 & 71.4 & 2 & 28.6 & & \\
\hline
\end{tabular}

NS non-significant, HS Highly significant

*Student's $t$ test

**Fisher exact test

***Absent Sliding Score 2 weeks after pleurodesis: A (absent in more than 6 areas) and B (absent in 4 to 6 areas)

which would avoid mesothelial irritation occurring with the presence of the drain in the pleural space for a prolonged time. Activation of the pleural mesothelial cells by malignant cells, bacteria, and chemokines mediated activation results in increased capillary permeability and formation of pleural fluid [17].

One advantage of the single-session technique used in the current study was to shorten the duration of pleural fluid aspiration and to remove the pigtail as rapidly as possible to avoid further mesothelial irritation especially by bacteria with prolonged pigtail insertion. No other studies considered the impact of duration of pleural fluid drainage on pleurodesis outcome. In this study, drainage of $2815 \pm 881.55 \mathrm{ml}$ of pleural fluid was done over a range of 1 to $3 \mathrm{~h}(1.65 \pm 0.70 \mathrm{~h})$ depending on the clinical state of each patient.

In this study, there was no significant correlation between the outcome of pleurodesis and the amount of the


Fig. 1 ROC curve and coordinates for the best cutoff duration of pleural fluid aspiration till pleurodesis.

*The shown hour was proposed for predicting pleurodesis success in our patient series. ROC, receiver operating characteristic; AUC, area under the curve 
Table 5 Relation between Pleural Adherence Score (PAS) after $24 \mathrm{~h}$ and Absent Sliding Score (ASS) after 2 weeks

\begin{tabular}{lllllll}
\hline & \multicolumn{3}{l}{ PAS after $24 \mathrm{~h}$} & \multirow{2}{*}{$F^{*}$} & $p$ value \\
\cline { 2 - 4 } & Mean & SD & & \\
\hline **ASS after 2 weeks & A & 15.50 & 1.08 & 174.40 & $<0.001 \mathrm{HS}$ \\
& B & 11.75 & 0.46 & & \\
\hline
\end{tabular}

*One-way ANOVA test

**ASS Absent Sliding Score: A (absent sliding in more than 6 areas) and B (absent sliding in 4 to 6 areas)

pleural fluid drained, but there was a highly significant correlation with the duration of fluid drainage ( $p$ value 0.001) (Table 4). No previous data were found about how the duration of pleural fluid aspiration could affect the outcome of pleurodesis. In the current study, a duration of $2.5 \mathrm{~h}$ or less was statistically proposed as a cutoff value not to exceed for successful pleurodesis with sensitivity of $100 \%$ and specificity of $100 \%$ (Fig. 1).

In this work, $2 \mathrm{~h}$ after pleurodesis and before pigtail removal, ultrasonographically detectable residual pleural fluid was actively aspirated. An average amount of 33.25 $\pm 23.64 \mathrm{ml}$ was drained. This amount of pleural fluid did not significantly affect the outcome as no significant difference was found between cases of successful and failed pleurodesis $33.33 \pm 16.76$ versus $32.50 \pm 3.54$, respectively ( $p$ value 0.95 ).
Corcoran and colleagues innovated an ultrasoundderived Pleural Adherence Score (PAS) to facilitate the early prediction of long-term outcomes after chemical pleurodesis using talc pleurodesis in MPE. They found that there was a significant difference between the mean total Pleural Adherence Score at day 1 for patients with successful and failed pleurodesis 13.36 versus 6.75, respectively, with a $p$ value of 0.0023 . A total Pleural Adherence Score of 10 or more at day1 (sensitivity $82 \%$, specificity 91\%) was used as the cutoff for hypothetical pleurodesis success after chest tube removal [4]. The authors recommended further research to validate the results.

In our study, PAS $24 \mathrm{~h}$ after pleurodesis was ranging from 5 to 17 with a mean 13.37. PAS was higher in those with successful pleurodesis than the 2 cases who experienced reaccumulation of pleural fluid, but this did not reach a statistically significant difference 14.27 versus 11.50 ( $p$ value 0.08 ) (Table 4 ). This can be explained by the small number of failed pleurodesis in the study population which played an important role in this statistically non-significant relation. A total Pleural Adherence Score of 11 or more after $24 \mathrm{~h}$ from pleurodesis (sensitivity $93 \%$, specificity 50\%) (Fig. 2) was statistically proposed as a cutoff value for pigtail removal and expected successful pleurodesis.

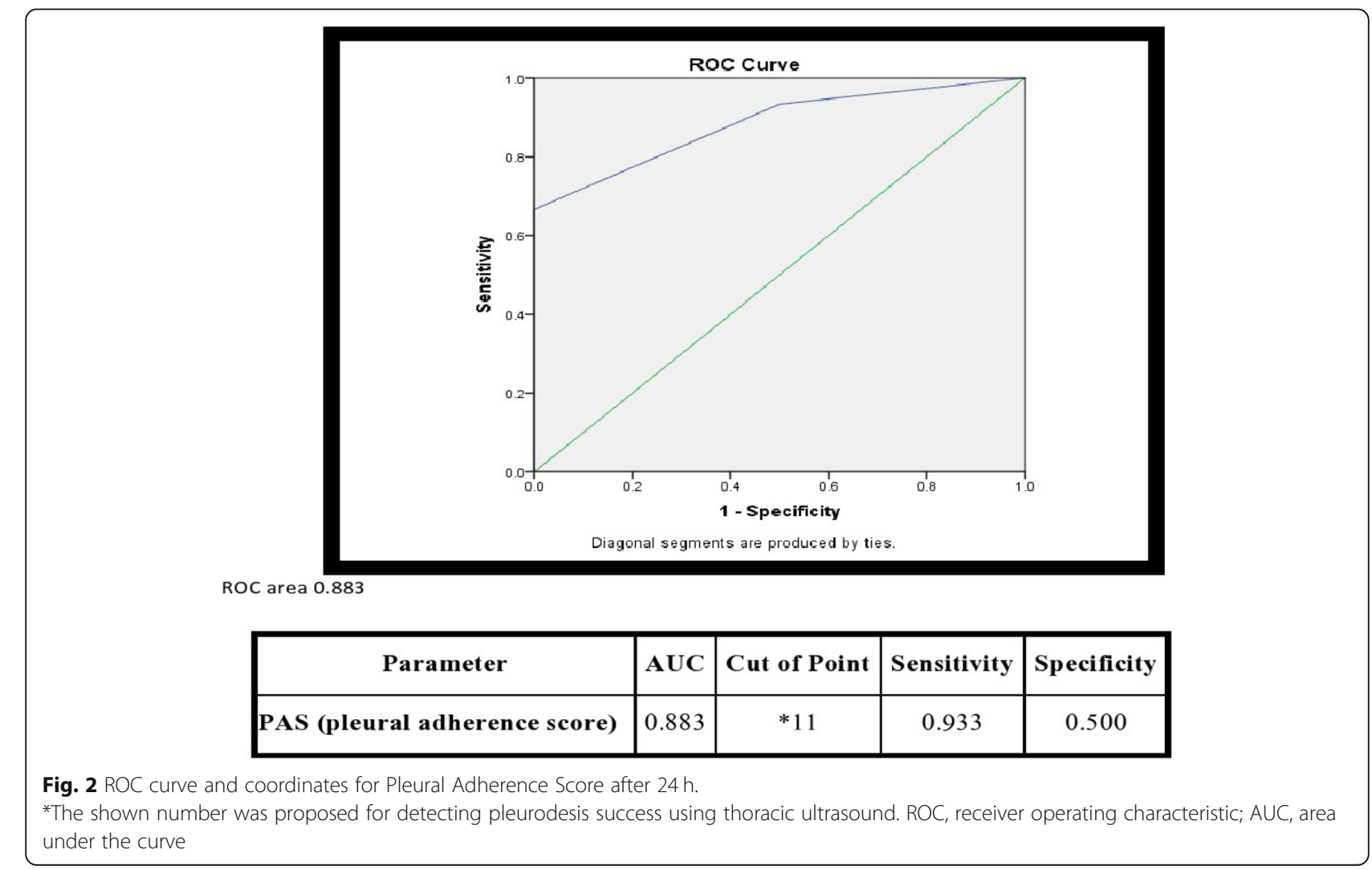


An important positive outcome in this study was the mean time of hospital stay related to the procedure which was $9.88 \pm 3.12 \mathrm{~h}$. This time included the time needed for the preparation for, the performance of the procedure, and the time needed for the observation for complications/discomfort after the procedure. This shortened total hospital stay was due to the intended rapid complete pleural drainage and pleurodesis. This technique definitely offers a greatly cost-effective outcome compared to the traditional procedure.

This study had some limitations; the small number of studied population and blinded assessors may be needed to strengthen the work and give no chance to bias. Wide-scale implementation of the technique on a larger number of patients and longer follow-up periods are recommended to validate the efficiency of single-session pleurodesis.

\section{Conclusion}

An ultrasound-guided completion of the process of pleurodesis in a single session with shorter duration of pleural fluid drainage and shorter hospital stay (can be done on a day-care basis) is efficient, safe, and costeffective. This technique is strongly recommended to replace the traditional practice of keeping the indwelling pleural drain for several days waiting for the cessation of pleural fluid reaccumulation. An ultrasound-derived Absent Sliding Score can be used as early as day 1 and day 15 to confirm pleural adherence and to expect the outcome of pleurodesis.

\section{Abbreviations}

MPE: Malignant pleural effusion; PAS: Pleural Adherence Score; ASS: Absent Sliding Score

\section{Acknowledgements}

Deep gratitude to all patients accepted to participate in the study.

\section{Authors' contributions}

Magdy Mohamed Khalil put the design of the work, interpreted the data, and revised it. Hieba Gamal Ezzelregal performed the procedure, data acquisition, and analysis, and was a major contributor in writing the manuscript. All authors have read and approved the final manuscript.

\section{Funding}

Not available

\section{Availability of data and materials}

The datasets used during the current study are available from the corresponding author on reasonable request

\section{Ethics approval and consent to participate}

The study was approved by the Ethical Committee Board of Ain Shams University and in accordance with the Declaration of Helsinki (the reference number is not available). An informed verbal consent was taken from all enrolled patients; all patients were adults; the process of pleurodesis itself was not new but only the rapid technique. Written consent was not necessary according to the national regulations.

\section{Competing interests}

The authors declare that they have no competing interests.

Received: 8 April 2020 Accepted: 21 May 2020

Published online: 30 June 2020

References

1. Fouad Atsai T H, Wu Sh G, Chang Y L, Wu Ch T, Tsai M F, Wei P F, et al. (2012) Effusion immunocytochemistry as an alternative approach for the selection of first-line targeted therapy in advanced lung adenocarcinoma. J Thorac Oncol 7(suppl 6):993-1000

2. Antunes G, Neville E, Duffy J, Ali N (2003) BTS guidelines for the management of malignant pleural effusions. Thorax 58:29

3. Heffner JE (2008) Diagnosis and management of malignant pleural effusions. J Repirology 1(13 suppl):5-20

4. Corcoran JP, Hallifax RJ, Mercer RM, Yousuf A, Asciak R, Hassan M et al (2018) Thoracic ultrasound as an early predictor of pleurodesis success in malignant pleural effusion. Chest 154(suppl 5):1115-1120

5. Antony VB, Loddenkember R, Astoul P, Boutin C, Goldstrawz P, Hott J et al (2001) Management of malignant pleural effusions. Eur Respir J 18:402-419

6. Maddams J, Utley M, Møller H (2012) Projections of cancer prevalence in the United Kingdom, 2010-2040. British Journal of Cancer 107(suppl 7): 1195-1197

7. Roberts ME, Neville E, Berrisford RG, Antunes G, Ali N (2010) Management of a malignant pleural effusion: British Thoracic Society pleural disease guideline. Thorax 65(suppl 2):32-40

8. Zhu Z, Donnelly E, Dikensoy O, Misra H, Bilaceroglu S, Lane KB et al (2005) Efficacy of ultrasound in the diagnosis of pleurodesis in rabbits. Chest 128(suppl 2):934-939

9. Bilaceroglu S, Guo Y, Hawthorne ML, Zhu Z, Stathopoulos GT, Lane KB et al (2005) Oral forms of tetracycline and doxycycline are effective in producing pleurodesis. Chest 128(suppl 5):3750-3756

10. El Hadidy AA, Kamel KM, Zaid AA, Kamal E, Fayaid HE (2017) Role of chest ultrasound in detecting successful pleurodesis. Egyptian J Chest Dis Tuberculosis 66(suppl 2):279-283

11. Johnston WW (1985) The malignant pleural effusion. A review of cytopathologic diagnoses of 584 specimens from 472 consecutive patients. Cancer 56(suppl 4):905-909

12. Tettey M, Sereboe L, Edwin F (2005) Frimpong-Boateng K, Tetracycline pleurodesis for malignant pleural effusion-a review of 38 cases. GMJ 39(suppl 4):128-131

13. Dietrich CF, Mathis G, Cui XW, Ignee A, Hocke M, Hirche TO (2015) Ultrasound of the pleurae and lungs. Ultrasound Med Biol 41(suppl 2):351365

14. Sasaki M, Kawabe M, Hirai S, Yamada N, Morioka K, Ihaya A et al (2005) Preoperative detection of pleural adhesions by chest ultrasonography. The Annals of Thoracic surgery 80(suppl 2):439-442

15. Mourad IA, Abdel Rahman AR, Aziz Sh A, Saber NM (2004) Pleurodesis as a palliative treatment of advanced lung cancer with malignant pleural effusion. J Egypt Natl Canc Inst 16(suppl 3):188-194

16. Bakr R M, El- Mahalawy I I, Abdel- Aal G A, Mabrouk A A, Ali A A, Pleurodesis using different agents in malignant pleural effusion. Egypt J Chest Dis Tuberculosis 2012; 61 suppl 4:399-404.

17. Batra H, Antony VB (2015) Pleural mesothelial cells in pleural and lung diseases. J Thoracic Dis 7(suppl 6):964-980

\section{Publisher's Note}

Springer Nature remains neutral with regard to jurisdictional claims in published maps and institutional affiliations. 